\title{
Organization and evolution of the chalcone synthase gene family in bread wheat and relative species
}

\author{
Anastasia Y. Glagoleva ${ }^{1 *}$, Nikita V. Ivanisenko ${ }^{1,2}$ and Elena K. Khlestkina ${ }^{1,2,3}$ \\ From 11th International Multiconference "Bioinformatics of Genome Regulation and StructurelSystems Biology" - BGRSISB- \\ 2018
}

Novosibirsk, Russia. 20-25 August 2018

\begin{abstract}
Background: Flavonoid compounds are secondary plant metabolites, having a functional importance in plant development, protection from pathogens and unfavorable environmental factors. Chalcone synthase (CHS) is a key enzyme in the biosynthesis of flavonoids; it is involved in biosynthesis of all classes of flavonoid compounds. Nevertheless, the Chs gene family in bread wheat (Triticum aestivum L.) has been not characterized yet. The aim of the current study was to investigate structural and functional organization of the Chs genes and evolution of this gene family in bread wheat and relative species.

Results: The nucleotide sequences of the eight Chs copies in T. aestivum were identified. Among them, two homoeologous sets of the Chs genes were located on the short (Chs-A1, -B1, -D1) and the long (Chs-A4, -B4, -D4) arms of homoeologous group 2 chromosomes. Two paralogous gene copies in the B-genome (Chs-B2, $-B 3)$ were located in the distal regions of 2BS chromosome. To clarify the origin of Chs duplications in the B-genome the phylogenetic analysis with the Chs sequences of Triticum and Aegilops species carrying ancestral genomes was conducted. It was estimated that the first duplication event occurred in the genome of the common ancestor of Triticum and Aegilops genera about 10-12 million years ago (MYA), then another copy was formed in the ancestor of the B-genome about 6-7 MYA. A homology modeling revealed high sequence similarity of bread wheat CHS enzymes. A number of short deletions in coding regions of some Chs sequences are not expected to have any significant functional effects. Estimation of transcriptional activity of the Chs copies along with a comparative analysis of their promoters structure suggested their functional specialization, which likely contributed to the maintaining of the duplicated Chs genes in wheat genome.

Conclusions: From possible ten Chs copies in bread wheat genome, eight members of this family retained their intact structure and activity, while two copies appear to be lost at the level of diploid and tetraploid ancestors. Transcriptional assay along with a comparative analysis of the cis-regulatory elements revealed their functional diversification. The multiple functions supported by the Chs family are assumed to be a driving force for duplications of the Chs gene and their retention in plant genome.
\end{abstract}

Keywords: CHS, Chalcone synthase, Gene duplication, Flavonoid biosynthesis, Triticum, Aegilops

\footnotetext{
* Correspondence: glagoleva@bionet.nsc.ru

${ }^{1}$ Institute of Cytology and Genetics SB RAS, Novosibirsk, Russia

Full list of author information is available at the end of the article
}

(c) The Author(s). 2019 Open Access This article is distributed under the terms of the Creative Commons Attribution 4.0 International License (http://creativecommons.org/licenses/by/4.0/), which permits unrestricted use, distribution, and reproduction in any medium, provided you give appropriate credit to the original author(s) and the source, provide a link to the Creative Commons license, and indicate if changes were made. The Creative Commons Public Domain Dedication waiver (http://creativecommons.org/publicdomain/zero/1.0/) applies to the data made available in this article, unless otherwise stated. 


\section{Background}

Flavonoid compounds are secondary plant metabolites playing important role in plant development [1], protection against pathogens $[2,3]$ and environmental stresses such as UV light, drought, salinity, wounding, extreme temperatures $[4,5]$. Flavonoids are antioxidants due to their ability to terminate free radical reactions and to protect the plants from oxidative stress [6]. Also, most of flavonoids are colored compounds, that made genes involved in their synthesis to be a convenient model for genetic studies [7]. The compounds are synthesized through the flavonoid biosynthesis pathway that starts from the condensation of three molecules of malonyl-CoA with one molecule of 4-coumaroylCoA with forming naringenin chalcone [8]. The reaction is catalyzed by chalcone synthase (CHS; EC 2.3.1.74), that belongs to polyketide synthases type III family.

The Chs genes are well-characterized in many plant species. Comparison of the Chs gene sequences from different species revealed that the Chs gene is structurally conserved, and most of the genes contain two exons and one intron. In all plant species, the CHS enzymes have the strictly conserved catalytic center consisted of four residues: Cys164, His303, Asn336, and Phe215 [9].

The Chs genes are generally represented in plant genomes by multiple copies forming gene families. Gene families can arise through gene duplications and subsequent nucleotide substitutions [10]. In some cases, duplicated genes increase the total amount of enzyme [11]. In other cases, gene family members can acquire new functions (neofunctionalization) [2] or can undergo the functional divergence establishing distinct complementary effects (subfunctionalization) $[3,12]$. All cases were involved in plant adaptation to environments.

Bread wheat (Triticum aestivum L., $2 n=6 x=42$, BBAADD) originated from different ancestral diploid species, related to nowadays existing Triticum urartu $(2 n=2 x=14, \mathrm{AA})$, Aegilops speltoides $(2 n=2 x=14$, SS), and Aegilops tauschii ( $2 n=2 x=14$, DD) [13]. Because of the fusion of three genomes, most genes are present in three functional copies. They are referred to homoeologous genes. Non-additive gene expression of homoeologs from transcriptional divergence in different tissues or developmental stage up to epigenetic silencing has been widely reported [14-18].

In bread wheat, the Chs genes family has been not characterized yet. The aim of the current study was to investigate structural and functional organization of the Chs gene family and its evolution in bread wheat and relative species.

\section{Results}

The Chs gene copies identification and mapping

According to the known Chs gene sequence of barley Hordeum vulgare L. (X58339.1) the nucleotide sequences of the eight Chs copies in T. aestivum were identified in URGI database using a BLAST algorithm. The identified Chs copies were located on homoeologous group 2 chromosomes. Among them three homoeologous copies in the A-, B- and D-genomes (Chs-A1, $-B 1$ and $-D 1$ ) and two paralogous copies in the B-genome $(C h s-B 2,-B 3)$ were mapped using nulli-tetrasomic and deletion lines in the distal regions of 2AS, 2BS and 2DS chromosomes (Additional file 1). Three additional Chs copies (Chs-A4, $-B 4,-D 4)$ were identified on the long arms of homoeologous group 2 chromosomes.

The Chs gene sequences of different Triticum and Aegilops species (tetraploid T. durum $(2 n=4 x=28)$ and diploid T. urartu, T. monococcum, Ae. speltoides, Ae. sharonensis, and Ae. tauschii $(2 n=2 x=14))$ were also identified, annotated and used for phylogenetic analysis. The sequence of Chs-A1 of T. durum was partially obtained by sequencing its PCR product. The identified copies are listed in Additional file 2: Table S2. Using FGENESH software the exon-intronic structure was determined: all Chs copies consist of two exons and one intron. The length of the coding sequence is $1185 \mathrm{bp}$. In sequences of several Chs copies (Chs-A4 T. monococcum, Chs-A3, $-A 4$ T. urartu) the short deletions with frameshift in protein coding regions were observed.

\section{The origin of Chs duplicated copies}

To clarify the origin of paralogous Chs duplications in the B-genome, we compared sequences of the T. aestivum Chs genes with their homologs in different Triticum and Aegilops species carrying the genomes $\mathrm{A}, \mathrm{B}(\mathrm{S})$ and $\mathrm{D}$. A phylogeny of the Chs copies is presented in Fig. 1. The Chs sequence of Hordeum vulgare (X58339.1), Oryza sativa (AB058397.1) and Zea mays (AY728478.1) were used as an outgroup.

For prediction the divergence time of the Chs copies in the B-genome, we used the number of synonymous substitutions between copies and the known time of divergence between Hordeum and Triticum (about 11 MYA). It was calculated that the first Chs gene duplication event leading to Chi-B3 took place in the common ancestor of Triticum and Aegilops about 10-12 MYA. Then, the Chi-B2 copy was formed in the ancestor of the B-genome about 6-7 MYA. The homoeologs (orthologs) of the Chs-B3 copy are preserved in the A- and D-genomes of diploid and tetraploid species, but they were likely pseudogenized in T. aestivum $2 \mathrm{~A}$ and $2 \mathrm{D}$ chromosomes. To confirm this assumption the primers specific for the Chs-A3 sequences of T. durum, T. monococcum and $T$. urartu were designed. It was shown that the Chs-A3 copy was preserved in diploid and tetraploid wheat species carrying A-genome, while in hexaploid wheat genomes this copy is absent (Table 1, Additional file 3). The Chs-B2 copy does not have 


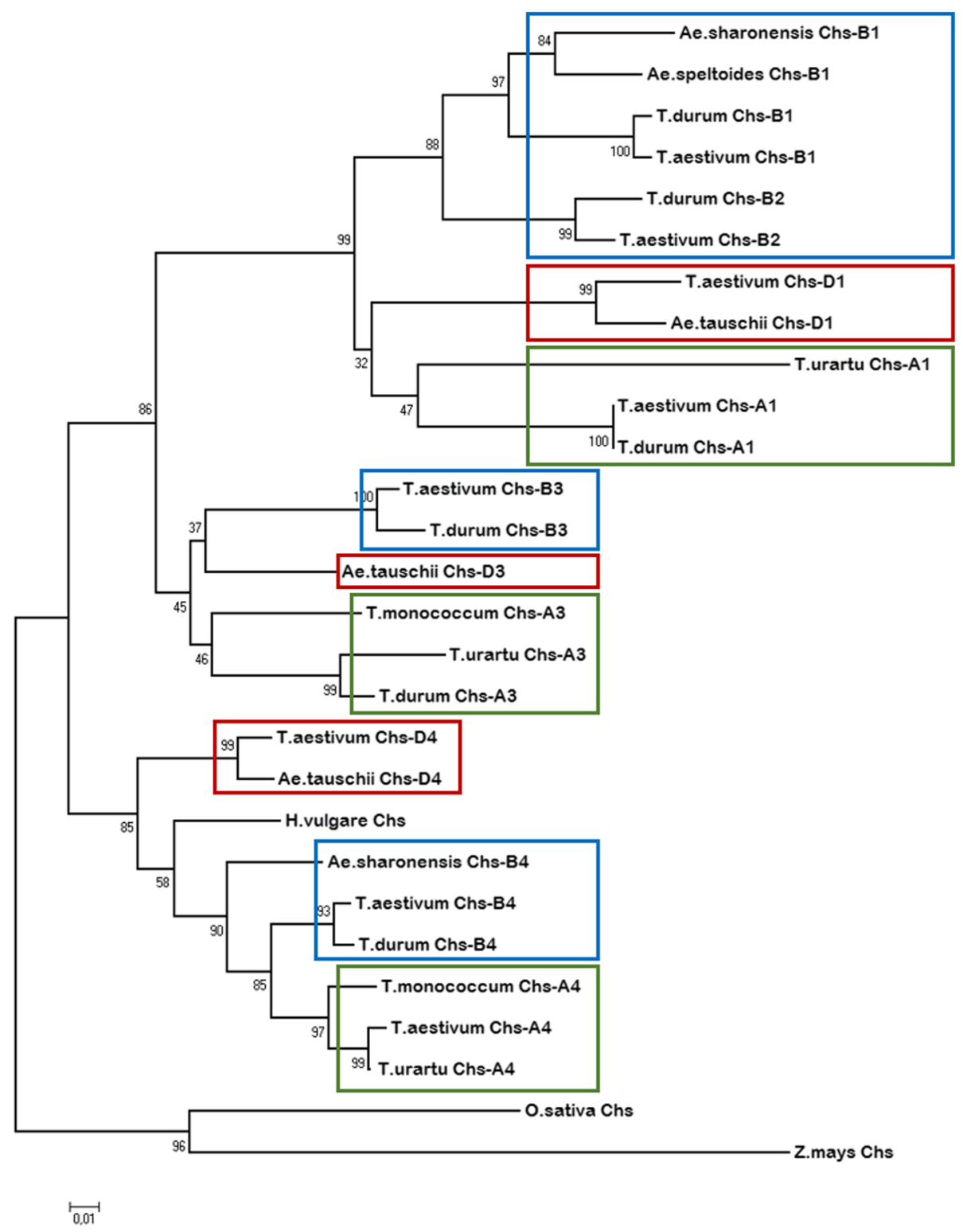

Fig. 1 The Neighbour-Joining tree of the Chs genes of Triticeae species. The B/S-genomic copies are highlighted in blue frames, A-genomic - in green, D-genomic - in red

orthologs in the A and D genomes since it has occurred as the Chs-B1 copy duplication in the ancestor of the $\mathrm{B}$-genome (Fig. 1). The time of divergence between the Chs copies from $2 \mathrm{~S}$ and $2 \mathrm{~L}$ chromosome lines is about 15 MYA.

\section{Structural organization of the Chs copies}

We used a homology modeling to analyze the effects of amino acid variability observed for Chs genes in bread wheat. All bread wheat CHS enzymes have high sequence similarity and more than $90 \%$ similarity with chalcone synthase from Medicago sativa $\mathrm{L}$. with available crystal structures. The predicted homology model of CHS dimer enzyme in complex with CoA and naringenin are shown in Fig. 2. Presumably, all bread wheat predicted sequences encode functionally active chalcone synthases.

In some Chs sequences, we observed a number of short deletions in protein coding region (Additional file 4: Figure S1). The short deletion of one amino acid residue in T. monococcum Chs-A4 sequence is located in the loop not involved directly in the catalytic activity of CHS, therefore we do not expect significant functional effects. Structural analysis of short deletion observed in T. urartu Chs-A4 sequence showed that CHS can keep its function while binding specificity for CoA could be 
Table 1 The results of the test of different Triticum species carrying A-genome for presence of the Chs-A3 copy

\begin{tabular}{llll}
\hline Species & Genome & Number of samples & Expression \\
\hline Triticum aestivum L. & BBAADD & 4 & no \\
Triticum compactum Host & BBAADD & 1 & no \\
Triticum spelta L. & BBAADD & 1 & no \\
Triticum dicoccum (Schrank) Schübl & BBAA & 2 & yes \\
& & 3 & no \\
Triticum dicoccoides (Körn. ex Aschers. et Graebn.) Schweinf. & BBAA & 3 & yes \\
Triticum durum Desf. & BBAA & 1 & no \\
Triticum persicum Vav. & BBAA & 1 & no \\
Triticum timopheevii Zhuk. & GGAA & 1 & yes \\
Triticum urartu Thum. Ex Gandil & AA & 3 & yes \\
Aegilops speltoides Tausch. & SS & 3 & no \\
Aegilops tauschii Coss. & DD & 3 &
\end{tabular}

reduced due to loss of amino acid residues involved in recognition of phosphate group. Deletion observed in $T$. urartu Chs-A3 leads to shifting of the active site loop and active site residue C167 (Additional file 4: Figure S1). This residue is reported as the active-site nucleophile in polyketide formation [19]. According to [19] substitution of this residue still keeps catalysis of malonyl-CoA decarboxylation by CHS without chalcone formation.

We conducted an analysis of amino acid sequence variability among CHS variants of protein using FoldX. As a result, most of amino acid substitutions were predicted to be neutral or stabilizing structure of the CHS. In addition, high sequence variability was observed for amino acid residues located close to CoA binding site,

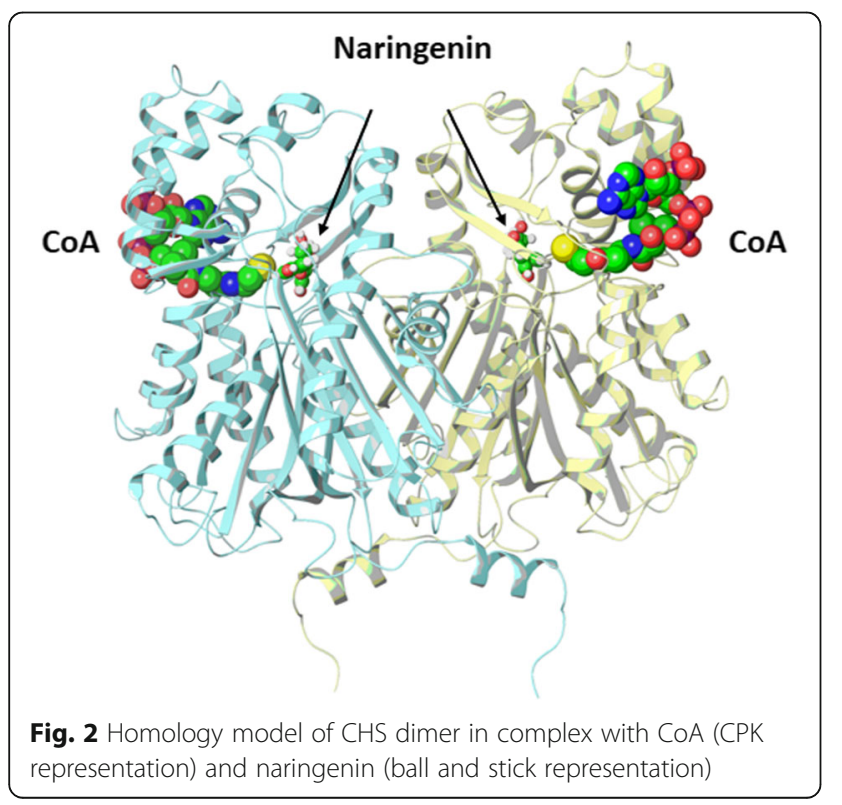

while in flavonoid binding site there were no amino acid substitutions. Two of the substitutions in question were shown to be highly destabilizing: A16E $\left(\Delta G_{\text {foldx }}=\right.$ $12.25 \mathrm{kcal} / \mathrm{mole})$ and C63R $\left(\Delta G_{\text {fold } x}=12.6 \mathrm{kcal} / \mathrm{mole}\right)$ of Ae. tauschii Chs-D1 and T. monococcum Chs-A4 respectively. A16E is located on the $\mathrm{N}$-terminal dimerization domain and therefore can be expected to reduce catalytic activity of $\mathrm{CHS}$ due to decrease of its dimerization propensity. C63 is located in hydrophobic region close to CoA binding site. According to FoldX, substitution to polar residue can lead to structural changes in CoA binding site. Indeed, we can expect that structural changes introduced by this substitution can lead to the formation of the salt bridge between R63 and D64 residues increasing its stability (Additional file 4: Figure S2).

\section{Functional diversification of the Chs copies}

We compared expression of the Chs-1, - 2, - 3 copies in different tissues: colored and uncolored pericarps, uncolored roots and coleoptiles with distinct pigmentation to test tissue specificity of the gene expression and dependence of their expression on the anthocyanin biosynthesis transcription factors. It was shown that all Chs copies are transcriptionally active, but they have different expression patterns (Fig. 3). All genes were active in the coleoptile, however, the genes were expressed independently on alleles of the $R c$ (red coleoptile) genes encoding MYB transcription factors, which define anthocyanin pigmentation and its intensity in coleoptiles. $C h s-B 2$ was expressed neither in the pericarp, nor in roots. It was active in the coleoptile of some genotypes only. Chs-B3 was the only gene that is transcribed in roots. With the exception of Chs-B2, all genes were active in the pericarp, but the expression was dependent on alleles of the $P p$ (purple pericarp) genes encoding the MYB and MYC 


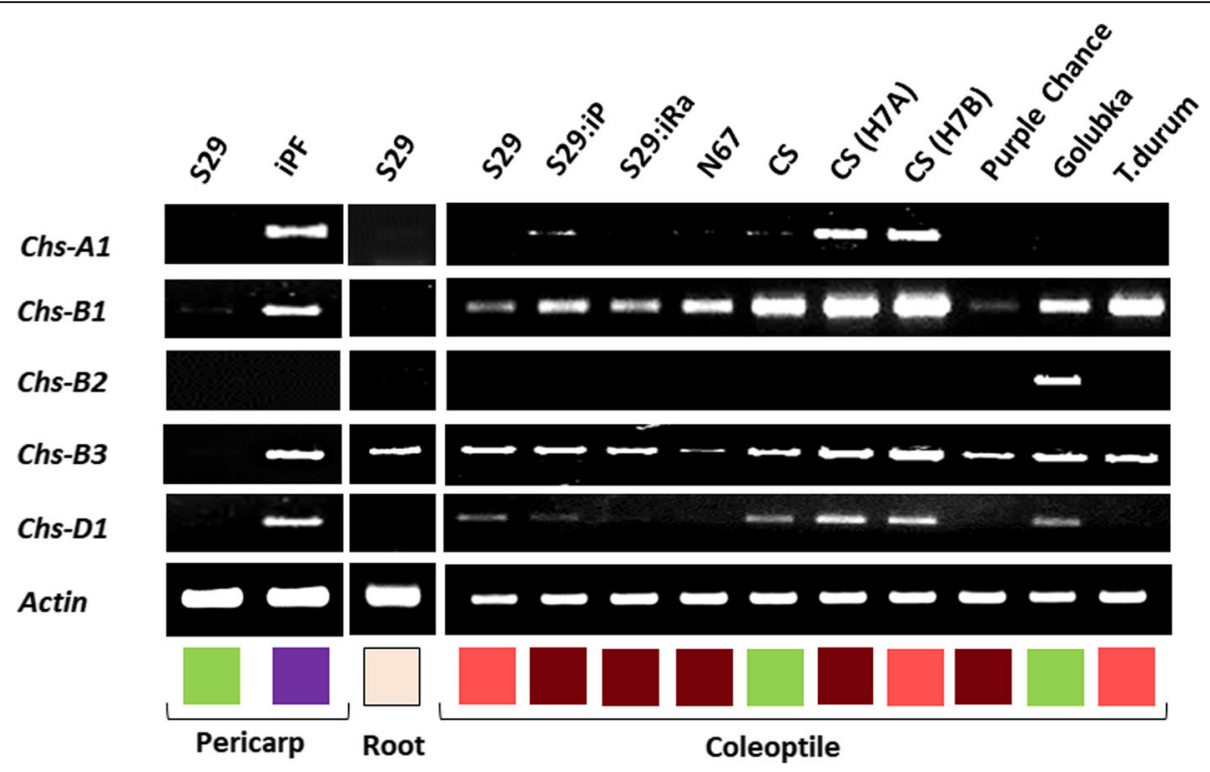

Fig. 3 Expression of the Chs copies in the pericarps, roots and coleoptiles. In squares the color and pigmentation intensity of wheat tissues are shown. The lines and cultivars names: S29 - Saratovskaya 29, iPF - i:S29 Pp1Pp2 ${ }^{P F}$ (PF - Purple Feed), iP - i:S29 Pp1Pp3 (P - purple), iRa - i:S29Ra, N67 - Novosibirskaya 67, CS - Chinese Spring, CS(H7A) - Chinese Spring (Hope 7A), CS(H7B) - Chinese Spring (Hope 7B), T.durum - accession number TRI 15744

regulatory factors. The observed color-dependent regulation of the Chs genes confirms the functionality of the MYB and MYC transcription factors binding sites that were predicted in promoters of the Chs gene copies (Fig. 4). In addition to the MYB and MYC binding sites, the cold and dehydration response cis-element and heat stress response cis-element were predicted in the Chs-B2 and $-D 1$ copies, respectively (Fig. 4). Overall, the data obtained demonstrated the functional divergence among the Chs-1, - 2, -3 gene copies in wheat. The Chs-A4, $-B 4,-D 4$ copies were highly identical to each other that did not allow design copy-specific primers for testing their individual expression levels.

\section{Discussion}

In this study, we identified the nucleotide sequences of the eight Chs genes in T. aestivum. All copies belong to class of chalcone synthases, but not to the other classes of polyketide synthases such as CHS-like or stilbene synthase (STS) [20]. All Chs copies were mapped to homoeologous group 2 chromosomes. It was shown that all copies have the same structure, consisting of two exons and one intron. The identified sequences showed the high level of coding sequences similarity (about 90\%).

The duplicated genes can arise from ploidy events and/or segmental gene duplications. In allopolyploid wheat, both events can occur. Among T. aestivum Chs

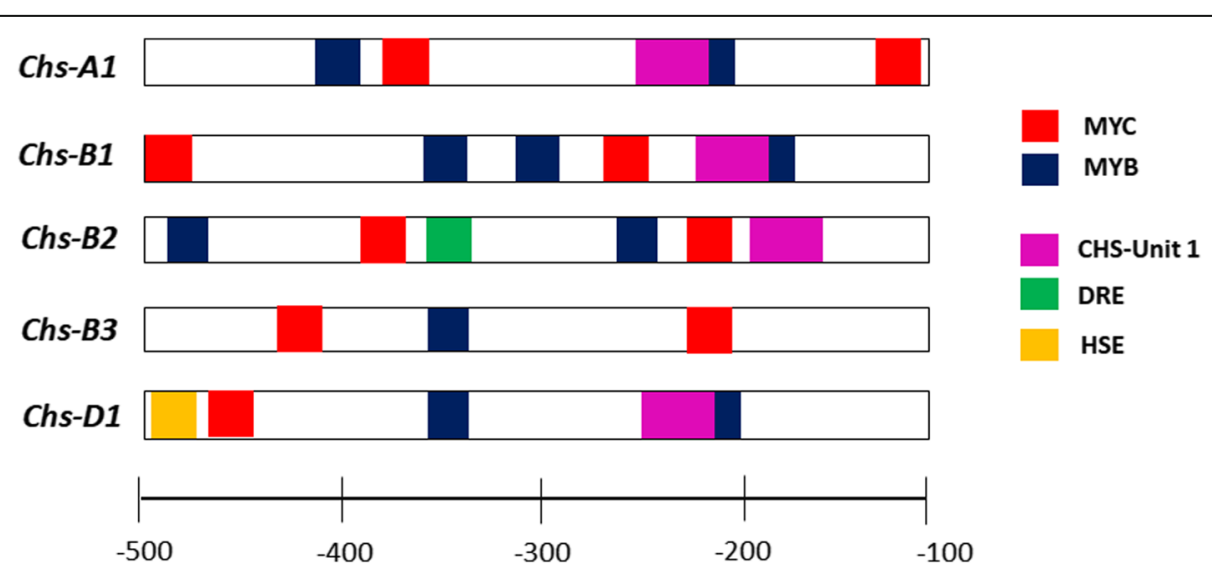

Fig. 4 Chs promoter structure. Cis-regulatory elements: MYB and MYC binding sites, CHS-Unit 1 - light responsive element, DRE - cold- and dehydration-responsive element, HSE - heat stress responsive element 
copies, we found two sets of homoeologous gene copies in the $\mathrm{A}-, \mathrm{B}-$ and $\mathrm{D}$-genomes $(C h s-A 1,-B 1,-D 1$ and Chs-A4, $-B 4,-D 4)$ and two paralogous gene copies in the B-genome (Chs-B2, $-B 3)$. The paralogous gene copies $C h s-B 2$ and $C h s-B 3$ were originated because of segmental duplication. Thus, we found four copies of the Chs gene in B-genome of $T$. aestivum. For instance, in diploid genomes of dicot plants, the Chs gene family is usually represented by 6 to 12 members. In Petunia hybrida, eight complete and four partial Chs genes were identified [21], in poplar and the morning glory (Ipomoea), the six Chs genes were found [2, 22]. In diploid genomes of monocots such as maize and rice, the 14 and 27 Chs genes were identified, respectively [23, 24].

It was calculated that the first Chs gene duplication event took place in the common ancestor of Triticum and Aegilops about 10-12 MYA, which led to the formation of Chs-B3 copy. Then, another copy $(C h s-B 2)$ was formed in the ancestor of the B-genome about 6-7 MYA. Orthologs of the Chs-B3 copy were preserved in the A- and D-genomes of diploid and tetraploid species, but the copies were likely pseudogenized in $T$. aestivum $2 \mathrm{~A}$ and 2D chromosomes. Pseudogenization of duplicated gene copies in hexaploid wheat genome is widely occurring during polyploidization and domestication [25]. For instance, 11 of 17 predicted copies of the $M y c$ gene were identified in $T$. aestivum, while six copies appear to be lost at the level of diploid ancestors [26]. It should be noted that a large number of wheat duplicated genes retain their functionality due to specialization [27, 28].The Chs-B2 copy also does not have orthologs in the $\mathrm{A}$ and $\mathrm{B}$ genomes, since the duplication occurred in the ancestor of the B-genome. The Chs $2 \mathrm{~L}$ copies occurred in the ancestor of Triticeae tribe about 15 MYA.

It was shown that all identified Chs genes in bread wheat have different patterns of expression. All Chs genes with the exception of $C h s-B 2$ are related to anthocyanin biosynthesis in the pericarp, that is governed by the MYBand MYC-responsive regulatory elements predicted in promoters of all copies. In coleoptiles, color-dependent regulation of the Chs copies was not observed. It can be explained by the different expression dynamics of the genes that dependent on genotypes. The Chs-D1 gene is possibly involved in synthesis of flavonoid compounds during heat stress defense, which is related to the presence of the corresponding element. Chs-B2 is not expressed in almost all genotypes, but unlike other copies, it has DRE elements in the promoter, associated with cold and drought resistance. Chs-B2 probably activates synthesis of flavonoid compounds under stress conditions. Previously the role of the Chs gene in response to abiotic stresses such as wounding, low temperature, drought, salinity and UV-light has been reported [29]. For example, the expression level of EaCHS1 from Eupatorium adenophorum in tobacco alters the accumulation of flavonoids and regulates plant tolerance to salinity stress by maintaining ROS homeostasis [30]. The accumulation of Chs mRNAs following wounding was observed in white spruce [31]. In other research the expression of the Chs gene in plants upon exposure to low temperature has been shown [32].Chs-B3 gene is expressed in all tissues examined including roots. In promoter region of this gene, light responsive elements and part of MYB-recognition element are absent. Probably, it is required for constitutive expression of CHS for the synthesis of a wide range of flavonoids. Such specialization can be a reason for the maintenance of these duplicated genes in bread wheat genome.

\section{Conclusions}

In the current study, we characterized the Chs genes family of bread wheat and its diploid and tetraploid relative species. Although some of the copies underwent pseudogenization, the identified eight Chs copies retained their intact structure and activity. Transcriptional assay along with a comparative analysis of the cis-regulatory elements revealed their functional diversification. The multiple functions supported by the Chs family are assumed to be a driving force for duplications of the Chs gene and their retention in the plant genome.

\section{Methods}

\section{Plant material and DNA/RNA extraction}

Samples of di-, tetra-, and hexaploid wheat species as well as Aegilops species maintained in collections of VIR, IPK and ICG used in the current study are listed in Additional file 2: Table S1. In addition, we used the complete set of cv. Chinese Spring nulli-tetrasomic lines [33] and a set of homoeologous group 2 chromosomes deletion lines [34] for chromosomal and intrachromosomal localization of the wheat Chs genes. DNA was extracted from the seven-day-old seedlings following the procedure described by Plaschke et al. [35]. The other genetic stocks are listed in Additional file 2: Table S1.

RNA was extracted from four-day-old coleoptiles, roots, colored and uncolored pericarp (early dough stage maturity, $\mathrm{BBCH}$ code 83 ) using QIAGEN Plant RNeasy kit (Hilden, Germany) followed by DNAse treatment applying RNase-Free DNase Set (QIAGEN, Hilden, Germany). For RNA extraction the seedlings were grown in climatic chamber «Rubarth Apparate» (RUMED $\mathrm{GmbH}$ ) at $20^{\circ} \mathrm{C}$ under a $12 \mathrm{~h}$ photoperiod. For RNA extraction from pericarp plants were grown at the Institute of Cytology and Genetics Greenhouse Core Facilities (Novosibirsk, Russia) under $12 \mathrm{~h}$ of light per day at $20-25^{\circ} \mathrm{C}$. 


\section{Identification of wheat Chs gene copies and sequence analysis}

Wheat Chs gene sequences search was performed using BLAST algorithm in three databases (https://urgi.ver sailles.inra.fr/blast/blast.php, http://www.cerealsdb.uk.ne t/cerealgenomics/CerealsDB/search_reads.php, www.ncb i.nlm.nih.gov/Database/) within genomic sequences of $T$. aestivum and its tetraploid (T. durum) and diploid ( $T$. monococcum, T. urartu, Ae. speltoides, Ae. sharonensis and $A$ e. tauschii) relatives. For the identified Chs copies of $T$. aestivum, the set of copy-specific primers was designed using IDT PrimerQuest software (http://eu.idtd na.com/PrimerQuest/Home/) (Table 2). The sequence of T. durum Chs-A1 copy was partially obtained using ABI PRISM 310 Genetic Analyzer (Perkin Elmer Cetus). Gene sequences were annotated using FGENESH software (Softberry Inc.,linux1.softberry.com/berry.phtml). The multiple alignment of gene sequences was performed using Multaline software [36]. Phylogenetic tree was constructed using MEGA 7 software [37] in conjunction with the Neighbor-Joining algorithm and 1000 bootstrap replicates. The number of synonymous (Ks) and non-synonymous (Ka) substitutions was evaluated following by Nei and Gojobori [38] method.
The cis-elements in promoters were predicted using PlantCARE software [39], The transcription start site was determined by the TSSP program (Softberry Inc., linux1. softberry.com/berry.phtml).

\section{Protein structure analysis}

Homology modeling was carried out using Modeller 9v12 [40]. Sequence alignments were obtained by Clustal-O program [41]. Model with the best DOPE score among 1000 generated models was selected. Crystal structure of chalcone synthase from Medicago sativa was used as the template (PDB identifier 1D6H; [19]). Crystal structure of $\mathrm{CHS}$ in complex with $\mathrm{CoA}$ and naringenin was obtained by structural superimposition with CHS/CoA (PDB identifier $1 \mathrm{D} 6 \mathrm{H}$ ) and $\mathrm{CHS} /$ Naringenin complexes (PDB identifier 1CKG; [9]). Estimations of impact of amino acid substitutions on stability were done using FoldX software [42]. The preliminary homology model was optimized using FoldX RepairPDB module.

\section{Chromosomal assignment of the wheat Chs gene copies and Chs-A3 copy searching}

PCR amplification from genomic DNA template of the cv. Chinese Spring nulli-tetrasomic and deletion lines was

Table 2 Chs copy-specific primers designed in the current study

\begin{tabular}{|c|c|c|c|c|}
\hline Purpose & Name & Sequence & Amplicon lengh (bp) & Annealing temperature $\left({ }^{\circ} \mathrm{C}\right)$ \\
\hline \multirow{10}{*}{$\begin{array}{l}\text { Copy identification, chromosomal } \\
\text { assignment and mapping, RT-PCR }\end{array}$} & \multirow[t]{2}{*}{ Chs-A1 } & Forward 5'TTGTATTCTGCACCACCTCG3' & \multirow[t]{2}{*}{265} & 62 \\
\hline & & Reverse 5'AAGAGTGCCTGACCTACCA3' & & 62 \\
\hline & \multirow[t]{2}{*}{ Chs-B1 } & $\begin{array}{l}\text { Forward } \\
\text { 5'TCGTCGTCGTGGAGGTT3' }\end{array}$ & \multirow[t]{2}{*}{256} & 56 \\
\hline & & $\begin{array}{l}\text { Reverse } \\
\text { 5TCGGAGCAGACCACCA3' }\end{array}$ & & 56 \\
\hline & \multirow[t]{2}{*}{ Chs-B2 } & $\begin{array}{l}\text { Forward } \\
\text { 5'ATGTATCAGCAGGGCTGT3' }\end{array}$ & \multirow[t]{2}{*}{279} & 54 \\
\hline & & $\begin{array}{l}\text { Reverse } \\
\text { 5'CTCTGAGTCCGGCAGAAT3' }\end{array}$ & & 54 \\
\hline & \multirow[t]{2}{*}{ Chs-B3 } & Forward 5'GAAGAGGTACATGCACCTG3' & \multirow[t]{2}{*}{481} & 53 \\
\hline & & $\begin{array}{l}\text { Reverse } \\
5^{\prime} \text { CGCACCGACGATCACG3' }\end{array}$ & & 57 \\
\hline & \multirow[t]{2}{*}{ Chs-D1 } & $\begin{array}{l}\text { Forward } \\
\text { 5'GATCACCCACCTTGTATT3' }\end{array}$ & \multirow[t]{2}{*}{257} & 49 \\
\hline & & $\begin{array}{l}\text { Reverse } \\
\text { 5'CGCCTGACCTACCAGT3' }\end{array}$ & & 54 \\
\hline \multirow[t]{2}{*}{ Chs-A3 group-specific } & \multirow[t]{2}{*}{ Chs_gs_A3 } & $\begin{array}{l}\text { Forward } \\
5^{\prime} \text { CCCACCTCGACTCGCTA3' }\end{array}$ & \multirow[t]{2}{*}{409} & 56 \\
\hline & & Reverse 5'GCACTTGACATGTTGCCATATT3' & & 54 \\
\hline \multirow[t]{4}{*}{ Sequensing } & \multirow[t]{4}{*}{ T.durum_A1 } & Forward_1 5'AGGAAGAGGTACATGCACCTT3' & \multirow[t]{2}{*}{567} & 56 \\
\hline & & Reverse_1 5'GATGGCACCCTCTGAGTCT3' & & 56 \\
\hline & & Forward_2 5'CGCTGGTAGGTCAGGCA3' & \multirow[t]{2}{*}{543} & 57 \\
\hline & & Reverse_2 5'CTGGGACACTATGGAGGACAA3' & & 56 \\
\hline \multirow[t]{2}{*}{ Reference } & \multirow[t]{2}{*}{ HvActin } & Forward 5'TCGCAACTTAGAAGCACTTCCG3' & \multirow[t]{2}{*}{130} & 60 \\
\hline & & Reverse 5'AAGTACAGTGTCTGGATTGGAGGG3' & & 60 \\
\hline
\end{tabular}


performed in $20 \mu \mathrm{l}$ reactions each containing $1 \mathrm{U}$ Taq DNA polymerase (Medigen Ltd.), 1x PCR buffer $(67 \mathrm{mM}$ TrisHCl, $\mathrm{pH} 8.8 ; 18 \mathrm{mM}\left(\mathrm{NH}_{4}\right)_{2} \mathrm{SO}_{4} ; 0.01 \%$ Tween 20$)$, $0.2 \mathrm{mM}$ dNTP and $0.25 \mu \mathrm{M}$ of each primers. 1.5 or 1.8 $\mathrm{mM} \mathrm{MgCl} 2$ was used for amplification of Chs-A1, $-B 3$ and $C h s-B 1,-B 2,-D 1$, Chs-gs- $A 3$ respectively. The amplification regime was initiated by a denaturing step $\left(94^{\circ} \mathrm{C} / 2\right.$ min), followed by 13 cycles of $94^{\circ} \mathrm{C} / 15 \mathrm{~s}, 65^{\circ} \mathrm{C} / 30 \mathrm{~s}$ with the temperature decrease in each cycle on $0,7^{\circ} \mathrm{C}, 72^{\circ} \mathrm{C} /$ $45 \mathrm{~s}$, when 24 cycles of $94{ }^{\circ} \mathrm{C} / 45 \mathrm{~s}, 56{ }^{\circ} \mathrm{C} / 30 \mathrm{~s}, 72^{\circ} \mathrm{C} / 45 \mathrm{~s}$ and completed with a final extension step of $72^{\circ} \mathrm{C} / 5 \mathrm{~min}$.

\section{RT-PCR}

Single-stranded cDNA was synthesized from $1 \mu \mathrm{g}$ total RNA using a $(\mathrm{dT})_{15}$ primer and a RevertAid ${ }^{\mathrm{ma}}$ kit (Thermo Fisher Scientific Inc., Waltham, MA, USA) in a $20 \mu$ reaction. RT-PCRs were conducted with the Chs copy-specific primers with the amplification regime and conditions describing above. The Actin gene sequence was used as a reference [43].

\section{Additional files}

Additional file 1: Intra-chromosomal localization of the Chs genes within the homoeologous group 2 chromosomes derived from the analysis of PCR profiles of deletion lines. (PDF $187 \mathrm{~kb}$ )

Additional file 2: Table S1. Wheat cultivars and accessions of Triticeae species using for PCR searching of Chs-A3 copy. Table S2. URGI contig numbers of identified Triticum and Aegilops sequences. (DOCX $21 \mathrm{~kb}$ )

Additional file 3: The PCR profile of Chs-A3 copy searching in different Triticum and Aegilops species. (PNG $37 \mathrm{~kb}$ )

Additional file 4: Figure S1. The illustration of the impact of short deletions to CHS protein structure. Figure S2. Analysis of amino acid substitutions in the wheat CHS sequence and estimation of impact of amino acid substitutions on protein stability. (DOCX $1111 \mathrm{~kb}$ )

\section{Abbreviations}

MYA: million years ego; MYB: myeloblastosis; MYC: myelocytomatosis; Pp: Purple pericarp; Rc: Red coleoptile

\section{Acknowledgements}

We thank Ms. Galina Generalova (ICG, Novosibirsk, Russia) for technical assistance.

\section{Funding}

Publication costs are funded by the Russian Foundation for Basic Research (16-04-00912). Growth of wheat plants in the ICG Plant Growth Core Facility was supported by ICG project 0324-2019-0039.

\section{Availability of data and materials}

The sequence obtained in the current study are available at NCBI: $\mathrm{MH} 704854$.

\section{About this supplement}

This article has been published as part of BMC Genetics Volume 20 Supplement 1, 2019: Selected articles from BGRSISB-2018: genetics. The full contents of the supplement are available online at https:// bmcgenet.biomedcentral.com/articles/supplements/volume-20supplement-1.

\section{Authors' contributions}

AYG performed molecular-genetic experiments, carried out in silico analysis and wrote the manuscript. NVI carried out in silico analysis of protein structures and participated in the drafting. the manuscript. EKK contributed to the conception and design of the study, to interpretation of data and to revising the manuscript critically. All authors read and approved the final manuscript.

\section{Ethics approval and consent to participate}

Not applicable.

\section{Consent for publication}

Not applicable.

\section{Competing interests}

The authors declare that they have no competing interests.

\section{Publisher's Note}

Springer Nature remains neutral with regard to jurisdictional claims in published maps and institutional affiliations.

\section{Author details}

${ }^{1}$ Institute of Cytology and Genetics SB RAS, Novosibirsk, Russia. ${ }^{2}$ Novosibirsk State University, Novosibirsk, Russia. ${ }^{3}$ N.I. Vavilov All-Russian Research Institute of Plant Genetic Resources (VIR), Saint-Petersburg, Russia.

Published: 18 March 2019

References

1. Taylor LP, Grotewold E. Flavonoids as developmental regulators. Curr Opin Plant Biol. 2005:8:317-23.

2. Durbin ML, McCaig B, Clegg MT. Molecular evolution of the chalcone synthase multigene family in the morning glory genome. Plant Mol Biol. 2000;42:79-92.

3. Han YY, Ming F, Wang W, Wang JW, Ye MM, Shen DL. Molecular evolution and functional specialization of chalcone synthase superfamily from Phalaenopsis Orchid. Genetica. 2006;128:429-38.

4. Khlestkina E. The adaptive role of flavonoids: emphasis on cereals. Cereal Res Commun. 2013:41:185-98.

5. Winkel-Shirley B. Biosynthesis of flavonoids and effects of stress. Curr Opin Plant Biol. 2002;5:218-23.

6. Brunetti C, Di FM, Fini A, Pollastri S, Tattini M. Flavonoids as antioxidants and developmental regulators: relative significance in plants and humans. Int J Mol Sci. 2013:14(2):3540-55.

7. Winkel-Shirley B. Flavonoid biosynthesis. A colorful model for genetics, biochemistry, cell biology, and biotechnology. Plant Physiol. 2001;126: 485-93

8. Heller W, Hahlbrock K. Highly purified "flavanone synthase" from parsley catalyzes the formation of naringenin chalcone. Arch Biochem Biophys. 1980;200:617-9.

9. Noel JP, Ferrer J-L, Jez JM, Bowman ME, Dixon RA. Structure of chalcone synthase and the molecular basis of plant polyketide biosynthesis. Nat Struct Biol. 1999;6:775-84.

10. Flagel LE, Wendel JF. Gene duplication and evolutionary novelty in plants. New Phytol. 2009;183:557-64.

11. Holding DR, Meeley RB, Hazebroek J, Selinger D, Gruis F, Jung R, et al. Identification and characterization of the maize arogenate dehydrogenase gene family. J Exp Bot. 2010;61:3663-73.

12. Ito $M$, Ichinose $Y$, Kato $H$, Shiraishi $T$, Yamada $T$. Molecular evolution and functional relevance of the chalcone synthase genes of pea. Mol Gen Genet. 1997;255:28-37.

13. Gill B, Friebe B. Cytogenetics, phylogeny and evolution of cultivated wheats. In: Curtis BC, Rajaram S, Gómez Macpherson H, editors. Bread wheat improvement and production. Rome: FAO; 2002. p. 71-88.

14. Adams KL, Cronn R, Percifield R, Wendel JF. Genes duplicated by polyploidy show unequal contributions to the transcriptome and organ-specific reciprocal silencing. PNAS. 2003;100(2):4649-54.

15. Bottley A, Xia GM, Koebner RMD. Homoeologous gene silencing in hexaploid wheat. Plant J. 2006;47:897-906.

16. Huo N, Zhang S, Zhu T, Dong L, Wang Y, Mohr T, et al. Gene duplication and evolution dynamics in the Homeologous regions harboring multiple 
Prolamin and resistance gene families in Hexaploid wheat. Front Plant Sci. 2018;9:673.

17. Shumayla SS, Kumar R, Mendu V, Singh K, Upadhyay SK. Genomic dissection and expression profiling revealed functional divergence in Triticum aestivum leucine rich repeat receptor like kinases (TaLRRKs). Front Plant Sci. 2016;7:1374.

18. Kashkush K, Feldman M, Levy AA. Gene loss, silencing and activation in a newly synthesized wheat allotetraploid. Genetics. 2002;160:1651-9.

19. Jez JM, Bowman ME, Dixon RA, Noel JP. Structure and mechanism of the evolutionarily unique plant enzyme chalcone isomerase. Nat Struct Biol. 2000;7:786-91.

20. Yang J, Gu H. Duplication and divergent evolution of the CHS and CHS-like genes in the chalcone synthase (CHS) superfamily. Chin Sci Bull. 2006;51:505-9.

21. Koes RE, Spelt CE, van den Elzen PJ, Mol JN. Cloning and molecular characterization of the chalcone synthase multigene family of Petunia hybrida. Gene. 1989;81:245-57.

22. Tsai CJ, WEI K, Harding SA. Populus, the new model system for investigating phenyl-propanoid complexity. Int J Appl Sci Eng. 2006;4(3):221-33.

23. Han Y, Ding T, Su B, Jiang H. Genome-wide identification, characterization and expression analysis of the chalcone synthase family in maize. Int J Mol Sci. 2016;17(2):161.

24. Han Y, Cao Y, Jiang H, Ding T. Genome-wide dissection of the chalcone synthase gene family in Oryza sativa. Mol Breed. 2017;37:119.

25. Brenchley R, Spannagl M, Pfeifer M, Barker GLA, D'Amore R, Allen AM, et al. Analysis of the bread wheat genome using whole-genome shotgun sequencing. Nature. 2012;491:705-10.

26. Strygina KV, Khlestkina EK. MYC gene family in cereals: transformations during evolution of hexaploid bread wheat and its relatives. Mol Biol. 2017; $51: 674-80$.

27. Qiao L, Zhang L, Zhang X, Zhang L, Li X, Chang J, et al. Evolution of the auX/IAA gene family in Hexaploid wheat. J Mol Evol. 2017;85:107-19.

28. Xu L, Tang Y, Gao S, Su S, Hong L, Wang W, et al. Comprehensive analyses of the annexin gene family in wheat. BMC Genomics. 2016;17:415.

29. Dao TT, Linthorst HJ, Verpoorte R. Chalcone synthase and its functions in plant resistance. Phytochem Rev. 2011;10(3):397-412.

30. Lijuan C, Huiming G, Yi L, Hongmei C. Chalcone synthase EaCHS1 from Eupatorium adenophorum functions in salt stress tolerance in tobacco. Plant Cell Rep. 2015;34:885-94.

31. Richard S, Lapointe G, Rutledge RG, Séguin A. Induction of chalcone synthase expression in white spruce by wounding and jasmonate. Plant Cell Physiol. 2000;41:982-7.

32. Shvarts M, Borochov A, Weiss D. Low temperature enhances petunia flower pigmentation and induces chalcone synthase gene expression. Physiol Plant. 1997:99:67-72.

33. Sears ER. Nullisomic analysis in common wheat. AmNat. 1953;87:245-52.

34. Endo TR, Gill BS. The deletion stocks of common wheat. J Hered. 1996;87: 295-307.

35. Plaschke J, Ganal MW, Röder MS. Detection of genetic diversity in closely related bread wheat using microsatellite markers. Theor Appl Genet. 1995; 91:1001-7.

36. Corpet F. Multiple sequence alignment with hierarchical clustering. Nucleic Acids Res. 1988;16:10881-90.

37. Kumar S, Stecher G, Tamura K, Dudley J. MEGA7: molecular evolutionary genetics analysis version 7.0 for bigger datasets downloaded from. Mol Biol Evol. 2016;33:1870-4

38. Nei M, Gojobori T. Simple methods for estimating the numbers of synonymous and nonsynonymous nucleotide substitutions. Mol Biol Evol. 1986:3:418-26.

39. Lescot $M$, Déhais $P$, Thijs $G$, Marchal $K$, Moreau $Y$, Van de Peer $Y$, et al. PlantCARE, a database of plant cis-acting regulatory elements and a portal to tools for in silico analysis of promoter sequences. Nucleic Acids Res. 2002;30:325-7.

40. Šali A, Blundell TL. Comparative protein modelling by satisfaction of spatial restraints. J Mol Biol. 1993;234:779-815.

41. Sievers F, Wilm A, Dineen D, Gibson TJ, Karplus K, Li W, et al. Fast, scalable generation of high-quality protein multiple sequence alignments using Clustal omega. Mol Syst Biol. 2011;7:539.

42. Schymkowitz J, Borg J, Stricher F, Nys R, Rousseau F, Serrano L. The FoldX web server: an online force field. Nucleic Acids Res. 2005;33:W382-8.

43. von Zitzewitz J, Szűcs P, Dubcovsky J, Yan L, Francia E, Pecchioni N, et al. Molecular and structural characterization of barley Vernalization genes. Plant Mol Biol. 2005;59:449-67.

Ready to submit your research? Choose BMC and benefit from:

- fast, convenient online submission

- thorough peer review by experienced researchers in your field

- rapid publication on acceptance

- support for research data, including large and complex data types

- gold Open Access which fosters wider collaboration and increased citations

- maximum visibility for your research: over $100 \mathrm{M}$ website views per year

At $\mathrm{BMC}$, research is always in progress.

Learn more biomedcentral.com/submissions 